\title{
Os Conceitos de Ajustamentos Ricardianos, Keynesianos e Schumpeterianos e a Questão do Emprego na Economia Brasileira
}

\author{
The Concepts of Ricardian, Keynesian and \\ Schumpeterian Adjustments and the Question of \\ Employment in the Brazilian Economy
}

RESUMO: O objetivo deste artigo é discutir a relação entre crescimento econômico, progresso técnico e geração de emprego, utilizando conceitos neo-schumpeterianos sobre o processo de ajustes disponíveis para todas as economias. Ele discute as possíveis trocas entre os três tipos de ajustes mais importantes — "Ricardiano", "crescimento" e "Schumpeteriano" - que representam, de fato, trocas entre crescimento de curto e longo prazo. Com base nessa concepção, discute os possíveis impactos da exploração de cada tipo de ajuste no nível de emprego brasileiro. Além disso, identifica preliminarmente os segmentos produtivos a serem estimulados, a fim de considerar simultaneamente a eficiência econômica e a geração de emprego. A principal conclusão é que, para associar geração de emprego, crescimento econômico e modernização, a economia brasileira deve investir não apenas nos segmentos mais dinâmicos do novo paradigma tecnológico, mas também nos segmentos tradicionais, porque possuem maior capacidade de geração de emprego.

PALAVRAS-CHAVE: Desenvolvimento econômico; análise neo-schumpeteriana; mudança estrutural; qualidade do emprego.

ABSTRACT: The aim of this paper is to discuss the relationship between economic growth, technical progress and employment generation, using Neo-schumpeterian concepts about the process of adjustments available to all economies. It discusses the possible trade-offs among the three kinds of the most important adjustments — "Ricardian ", "growth" and "Schumpeterian" - which represent, in fact, trade-offs between short and long-term growth. Based on this conception, it discusses the possible impacts of the exploration of each kind of adjustment on the Brazilian level of employment. In addition, it preliminarily identifies the productive segments to be stimulated in order to simultaneously consider economic efficiency and employment generation. The main conclusion is that to associate employment generation, economic growth and modernization, the Brazilian economy should invest not * Departamento de Economia da Universidade Federal de Viçosa - UFV, Viçosa/MG, Brasil. E-mail:
htsilvia@ufv.br. 
only in the most dynamic segments of the new technological paradigm, but also in the traditional segments, because they have a higher employment generation capacity.

KEYWORDS: Economic development; neo-Schumpeterian analysis; structural change; quality of employment.

JEL Classification: O40; O30; J81.

\section{INTRODUÇÃO}

O objetivo deste artigo é discutir as relações entre crescimento, progresso tecnológico e emprego a partir de elementos da teoria neo-schumpeteriana do desenvolvimento econômico. A discussão acerca de mudanças tecnológicas e de seu impacto sobre o mundo do trabalho é pertinente na medida em que o conjunto de transformações ora em curso na economia mundial alterou, consideravelmente, as configurações do mercado de trabalho estabelecidas após a Segunda Guerra Mundial. A relativa segurança dos trabalhadores, conquistada durante esse período, foi abalada em razão, principalmente, da volta do desemprego nas economias desenvolvidas, o qual tinha permanecido em níveis muito baixos durante as décadas de 1950 e 1960. O desemprego e suas consequências sobre o padrão de vida da população voltaram, assim, a estar entre as principais preocupações econômicas.

Do ponto de vista teórico, a discussão sobre a relação entre crescimento econômico, mudança tecnológica e desemprego é bastante antiga. A natureza dessa relação e as políticas sugeridas, contudo, não são matéria de consenso, dependendo do arcabouço teórico em que a análise está sustentada. Após a Segunda Guerra, por exemplo, houve o predomínio de ideias keynesianas de sustentação do nível de renda e de emprego, por meio de políticas geridas pelo Estado. Atingir o pleno-emprego passou a ser uma das prioridades dos governos, criando-se, inclusive, mecanismos de proteção ao trabalhador desempregado. Atualmente, há um retorno às premissas de que o mercado liberalizado permitiria maior crescimento econômico e geração de emprego. Acredita-se que a competitividade internacional será adquirida via abertura do mercado interno, expondo as empresas à forte concorrência e impelindo-as de modernizar-se. Da mesma forma, um mercado de trabalho mais flexível permitiria obter aumento de competitividade, dificultado atualmente pela inflexibilidade dos salários para baixo e pela existência de amplos benefícios trabalhistas. Acredita-se, ainda, que o desemprego atual, embora em parte estrutural, tenderá a diminuir conforme o crescimento for criando novos postos de trabalho, principalmente no setor terciário. Observa-se, assim, uma mudança de postura em relação ao emprego. Durante os períodos áureos de vigência do welfare state, a geração de emprego era uma variável-chave a ser considerada ao se traçar uma estratégia de desenvolvimento, constituindo-se com os altos salários e o conjunto de benefícios decorrentes do welfare state no padrão de desenvolvimento das economias capitalistas. Ou seja, um padrão no qual a manutenção da economia em nível próximo ao pleno-emprego e a garantia de altos salários asse- 
guravam um alto nível de demanda efetiva, de forma que crescimento econômico e bem-estar social estivessem relacionados positivamente. Na fase atual, ao contrário, a geração de emprego é vista mais como consequência do crescimento econômico do que como uma de suas causas, e esse, por sua vez, como decorrência do aumento da competitividade. $\mathrm{O}$ foco central passou a ser, assim, o poder competitivo do país, ficando a geração de emprego "a reboque" das políticas dirigidas à elevação da produtividade.

Esse enfoque, entretanto, não é consensual, haja vista as mudanças políticas recentes que têm ocorrido em alguns países europeus, como Inglaterra e França, neste final da década de 1990, em favor de partidos e governos que demonstrem maior preocupação com a questão do emprego.

Quando se trata de países com o perfil do Brasil, parece ainda mais premente colocar o emprego numa posição central dentro de uma política de desenvolvimento. Isso porque a busca de uma inserção mais competitiva na economia mundial, priorizando as atividades dinâmicas do novo paradigma industrial, pode trazer consequências ainda mais danosas do que aquelas experimentadas pelos principais países. Em primeiro lugar, diferentemente do que ocorreu nos países industrializados, em sociedades como a brasileira não houve a criação do estado de bem-estar, que poderia suavizar os problemas causados pelo desemprego; e, em segundo lugar, o desenvolvimento capitalista já produziu uma estrutura dual nesses países, de forma que uma alteração no mercado de trabalho, no sentido indicado anteriormente, pudesse agravar ainda mais a diferenciação entre a população.

No caso da economia brasileira, a reestruturação produtiva nos mesmos moldes do que vem acontecendo nos países líderes parece já estar produzindo resultados semelhantes em relação ao mundo do trabalho (ver, por exemplo, Baltar \& Henrique, 1994), sem contar, no entanto, com instituições que contrabalancem os efeitos negativos da modernização, como ocorre pelo menos parcialmente com os países da OCDE (Organização para Cooperação do Desenvolvimento Econômico). Entende-se, assim, que uma estratégia de desenvolvimento- para qualquer país, de forma geral, e para países com o perfil do Brasil, de modo particular — requer a incorporação do emprego, como variável-chave, nas políticas de crescimento e de modernização dos setores produtivos. Nesse sentido, a posição assumida neste trabalho contraria a priorização das políticas de crescimento em detrimento das políticas dirigidas à geração de emprego, sugerindo que deva ser encontrada uma solução que contemple essas questões conjuntamente.

Deve-se ressaltar, contudo, que uma política de desenvolvimento realmente eficiente não pode desconsiderar o mercado externo. Com o aumento das relações internacionais em todos os níveis, tornou-se impensável um modelo de desenvolvimento autárquico, isto é, orientado exclusivamente para o mercado interno. Nesse sentido, a política industrial a ser traçada para qualquer país deve enfatizar a produção de mercadorias visando, também, enfrentar a concorrência internacional, o que requer que a base da competitividade esteja assentada cada vez mais em vantagens de ordem superior, de acordo com a terminologia de Porter (1993, p. 62), ou seja, naquelas que se fundamentem, principalmente, em capacitação tecnológica. 
A discussão teórica a ser empreendida nas próximas seções pretende, assim, contribuir para o debate em torno da geração de crescimento, da geração de emprego e do aumento da competitividade internacional. Além disso, pretende-se identificar os segmentos produtivos que deveriam ser mais estimulados no Brasil, por de instrumentos de política industrial, de modo que permita uma melhor conciliação entre os diversos objetivos. Parte-se do pressuposto de que os segmentos produtivos a serem prioriza dos são idiossincráticos a cada país, ou seja, para cada um deles existe um conjunto de setores específicos que melhor se adequa às suas características. A escolha desse conjunto depende principalmente do grau de capacitação tecnológica do país, da história de desenvolvimento dos diversos segmentos, da configuração do mercado de trabalho de cada país e do perfil de distribuição de renda, entre outros fatores. No caso do Brasil, por exemplo, suas características requerem que o crescimento visando ao aumento da capacitação tecnológica do país - ou seja, sua modernização — não perca de vista a necessidade de incorporação de ampla camada da população ao mercado de consumo.

\section{TRADE-OFF ENTRE GERAÇÃO DE CRESCIMENTO NO CURTO E NO LONGO PRAZO}

A discussão em torno da geração de crescimento e da geração de emprego será empreendida com base em elementos da teoria neo-schumpeteriana do desenvolvimento econômico. Nesta seção, especificamente, procura-se discutir a geração de crescimento no curto e no longo prazo a partir de conceitos de Dosi (1988) sobre as possibilidades de ajustamentos disponíveis para todas as economias.

Segundo esse autor, uma economia capitalista pode efetuar três tipos diferentes de ajustamentos: "schumpeteriano", "de crescimento" e "ricardiano". O ajustamento "ricardiano" corresponde àquele que obedece aos sinais emitidos pelo mercado, de forma que a alocação de recursos entre os diversos segmentos produtivos ocorra segundo os preços relativos dos fatores - ou seja, segundo custos, preços dos insumos e lucratividades que o mercado indica. Esse tipo de ajuste implica, como a denominação sugere, a especialização da economia em segmentos produtivos que utilizam os recursos abundantes no país. O ajustamento "de crescimento" está vinculado ao aumento da demanda efetiva e relacionado à política e à taxa de investimento. Esse tipo de ajustamento corresponde a uma prática macroeconômica keynesiana. Por fim, o ajustamento "schumpeteriano" está voltado para as oportunidades tecnológicas abertas ao país, correspondendo a um esforço para o aumento da capacitação tecnológica, com o intuito de alcançar o upgrading industrial, bem como aumentar o poder competitivo da economia. Em suma, com o ajustamento "ricardiano", a economia ganha eficiência alocativa; com o "de crescimento", aumento de capacidade de produção; e, por fim, com o ajustamento "schumpeteriano" logra aumentar a capacitação tecnológica do país direcionando, na maioria das vezes, a produção para produtos com maior valor agregado.

Dosi admite que o desenvolvimento de todos os países comporta uma combi- 
nação dos três tipos de ajustamentos. Contudo, muitas vezes, surge um trade-off entre o primeiro tipo e os dois últimos, principalmente o "schumpeteriano". Surge, em outras palavras, um trade-off entre eficiência estática e dinâmica ${ }^{1}$, no sentido de que a obtenção da segunda parece requerer o sacrifício de vantagens aparentemente mais fáceis de serem exploradas. Isso porque a economia precisa realocar seus recursos produtivos para alcançar eficiência dinâmica, de modo aparentemente ineficiente, pelo menos no início. Segundo esse mesmo autor, nesses casos, para fazer ajustamentos "de crescimento" e "schumpeteriano", é necessário desobedecer aos sinais de mercado, isto é, pelo menos em princípio, agir de maneira contrária à racionalidade do mercado.

O trade-off entre ajustamentos do tipo "ricardiano" e "schumpeteriano" é mais facilmente visualizado, e surge quando os segmentos considerados mais eficientes pelo mercado não são aqueles mais dinâmicos. Já o trade-off entre ajustamentos do tipo "ricardiano" e "de crescimento", embora mais difícil de visualizar, ocorre quando o governo contraria os sinais emitidos pelo mercado, investindo em segmentos menos eficientes do ponto de vista alocativo, mas que tenham, por exemplo, maior encadeamento a jusante e a montante, sendo capazes de incrementar o crescimento econômico.

Assim, implementar investimentos que contrariem aos sinais de mercado implica um trade-off entre esses dois tipos de ajustamento - que geram eficiências dinâmicas - e o ajustamento "ricardiano" - que gera eficiência estática. Entre os dois tipos de ajustamentos capazes de gerar eficiência dinâmica, Dosi enfatiza o "schumpeteriano" como o mais importante, visto estar assentado em inovações que tendem a ampliar as oportunidades de investimento e a propiciar mudanças qualitativas nos padrões de produção, renda e consumo da economia.

Esses trade-offs tendem a se acentuar quando há o surgimento de novos paradigmas tecnológicos, uma vez que as trajetórias tecnológicas estão a princípio indefinidas, havendo muita incerteza quanto aos resultados econômicos das inovações preliminares. Nesse início é mais provável que os sinais de mercado sejam totalmente desfavoráveis aos investimentos em produtos e processos que utilizem novas tecnologias. Os trade-offs tendem a aumentar, também, quanto maior for a defasagem tecnológica, seja de uma empresa em relação à sua indústria, seja de um país em relação a outros. Quanto mais afastado estiver da fronteira tecnológica, mais o padrão de sinais será desfavorável às inovações. Para os países líderes, tecnologicamente pode ser que esse trade-off seja eliminado, na medida em que a exploração dos três tipos de eficiências seja conseguida por meio da alocação de recursos para os segmentos produtivos mais dinâmicos. Se os sinais de mercado captados por um país desenvolvido, por exemplo, requerer que os investimentos se dirijam para o complexo eletrônico - o mais dinâmico da atual fase do capitalismo - , não haveria contradição entre as três formas de ajustamentos. No entanto,

\footnotetext{
${ }^{1}$ Dosi denomina eficiência estática àquela procedente de alocação de recursos, enquanto eficiência dinâmica seria a decorrente de crescimento ou de construção de vantagens competitivas.
} 
se os sinais de mercado captados por um país pouco desenvolvido indicarem que os recursos deveriam ser canalizados, por exemplo, para o setor agrícola, haveria nesse caso trade-off entre eficiência "ricardiana" e "schumpeteriana", sobretudo.

Os casos acima mencionados, de surgimento do trade-off, poderiam ser caracterizados como, em outras palavras, a existência de trade-off entre o crescimento no curto e no longo prazo. No curto prazo, os investimentos em novas tecnologias e em determinados segmentos produtivos podem não ser os mais lucrativos, de maneira que o mercado sinalizaria de forma negativa a aplicação de recursos e esforços nesses setores. No longo prazo, porém, as novas tecnologias e os segmentos produtivos que as utilizam podem ser os mais promissores, em termos de aumentarem as oportunidades de investimentos e de conferirem maior competitividade e lucratividade para o país. Se o país, assim, obedecer somente aos sinais de mercado, fazendo unicamente ajustes "ricardianos", no longo prazo perderia competitividade em relação àqueles que estivessem empreendendo principalmente ajustamentos do tipo "schumpeteriano".

Historicamente, verifica-se que os países que têm aumentado seu poder competitivo são aqueles que desobedeceram aos sinais de mercado e canalizaram recursos para algumas áreas mais promissoras do ponto de vista tecnológico, como é o caso do Japão. A ideia central do enfoque neo-schumpeteriano, nesse ponto, é que a competitividade deve ser construída, e a principal arma para isso é o desenvolvimento tecnológico. O ajustamento "schumpeteriano" seria o principal responsável pelo aumento da competitividade de um país e, consequentemente, pelo seu desenvolvimento, mesmo que no curto prazo o padrão de sinais não seja favorável ao investimento em tecnologias que só serão promissoras no longo prazo. Para que fosse viável essa forma de ajustamento, deveria haver, assim como Dosi enfatiza, uma atuação relevante do Estado, cujo papel principal é o de melhorar os sinais emitidos pelo mercado, de modo que incentive investimentos nos segmentos mais dinâmicos.

Em suma, as economias dispõem de três tipos diferentes de ajustamentos, que podem ser combinados de diversas formas, de modo que aumente a eficiência econômica global. Acredita-se, contudo, que o planejamento econômico não pode visar apenas à eficiência econômica. Uma política de desenvolvimento realmente consistente precisa conciliar eficiência econômica e bem-estar social, o que implica que o emprego deve ser também contemplado num planejamento estratégico para a economia.

$\mathrm{Na}$ próxima seção pretende-se, assim, relacionar crescimento e geração de emprego a partir dos conceitos discutidos na presente seção.

\section{AS DIFERENTE S FORMAS DE AJUSTAMENTOS E O EMPREGO}

As diferentes formas de ajustamento disponíveis para uma economia afetam diretamente a variável emprego, como procurar-se-á demonstrar a seguir. Inicialmente, para relacionar o crescimento com o emprego, os três tipos de ajustamentos 
são classificados com base nos seguintes critérios: de um lado, supõe-se que a busca de eficiências "ricardianas" e "de crescimento" para a economia seja eficiente para gerar emprego no curto prazo; de outro, que a busca de eficiência "schumpeteriana" seja importante para gerar emprego mais do ponto de vista do longo prazo.

No curto prazo, a economia poderia gerar emprego por meio da melhoria na alocação de recursos- adotando, por exemplo, tecnologias que utilizem muita mão de-obra, no caso de esta ser um recurso abundante no país - permitindo o uso eficiente dos fatores de produção e através de políticas dirigidas ao aumento da demanda efetiva, o que acarretaria aumento de postos de trabalho mediante elevação da capacidade produtiva. No longo prazo, porém, a ênfase apenas nessas duas formas de ajustamentos poderia afetar de modo negativo o emprego, na medida em que implicasse apenas seu aumento horizontal, sem elevação da produtividade. A perda de competitividade do país em decorrência do reduzido investi mento em capacitação tecnológica comprometeria as possibilidades de geração de emprego.

No passado recente o problema do emprego era mais passível de ser resolvido, dando-se ênfase às duas formas de ajustamento acima mencionadas, na medida em que os países tinham maior autonomia em relação às suas políticas de desenvolvimento e as práticas protecionistas eram mais facilmente implementáveis. $\mathrm{Na}$ fase atual do capitalismo, contudo - de interação de todos os mercados - , a manutenção ou o aumento da competitividade tornaram-se fundamentais para sustentar determinado nível de emprego no país. Isso requer que a capacitação tecnológica do país se eleve, isto é, requer um ajuste do tipo "schumpeteriano".

A busca de eficiências "schumpeterianas", todavia, implica, na maioria das vezes, redução de emprego no curto prazo, dado que inovações decorrentes de novas tecnologias, em geral, acarretam economia de trabalho, como tem sido verificado historicamente. O investimento em capacitação tecnológica e em novas tecnologias afetam, no entanto, o emprego no longo prazo. Isso pode ser explicado da seguinte forma: em primeiro lugar, a manutenção ou o aumento da competitividade permitem ao país dinamizar sua produção em segmentos produtivos já existentes e, mesmo, implantar novos; em segundo, o investimento nos segmentos mais dinâmicos gera maiores oportunidades de investimentos adicionais, o que significa que aqueles tendem a aumentar sua participação relativa no produto total em detrimento de segmentos produtivos já explorados em antigos paradigmas tecnológicos ${ }^{2}$. Esse é o caso, por exemplo, do maior dinamismo do complexo eletrônico, mais passível de explorar o novo paradigma tecnológico, em relação a indústrias como de alimentos ou de calçados; e, em terceiro, o investimento em segmentos que utilizam mais as novas tecnologias permitem maior desenvolvimen-

\footnotetext{
2 Paradigma tecnológico é definido por Dosi (1984, p. 14-15) como certo padrão de resolução para problemas tecnológicos específicos, tendo como suporte os princípios de determinadas ciências naturais e as tecnologias de certos elementos materiais. Assim, por exemplo, a amplificação e a comutação de sinais elétricos estariam relacionadas a um paradigma tecnológico, baseado no desenvolvimento da física do estado sólido e tendo como elemento fundamental o silício.
} 
to das trajetórias tecnológicas ${ }^{3}$ relacionadas ao novo paradigma, o que influencia a competitividade futura do país. De modo geral, portanto, as implicações indicadas acima sugerem que a elevação da capacitação tecnológica do país influencia de forma substancial o emprego do país no longo prazo. Isso não significa afirmar deterministicamente que as oportunidades de emprego serão maiores no futuro utilizando-se novas tecnologias do que no presente empregando tecnologias antigas, uma vez que o surgimento de novos segmentos e a dinamização dos antigos podem não gerar tanto emprego como o antigo paradigma tecnológico permitia. A economia de trabalho nesse novo paradigma é brutal, de modo que não se possa saber $a$ priori se os novos empregos criados compensarão a eliminação dos antigos. O que se quer dizer é que as transformações ora em curso são irreversíveis, o que implica que o nível de emprego futuro do país depende de sua posição competitiva no cenário internaciona1. O nível de emprego futuro do país nessas condições depende, portanto, dos ajustamentos do tipo "schumpeteriano".

Dessa maneira, não apenas o ritmo de crescimento, mas a exploração das diversas formas de geração de eficiências, disponíveis para uma economia, afetam a variável emprego. Os ajustes dos tipos "ricardiano" e "de crescimento" permitem, sobretudo esse último, maior geração de emprego no curto prazo, mas menor emprego no longo. O ajuste "schumpeteriano", por sua vez, destrói empregos no curto prazo, mas é o mais promissor quando se considera o longo prazo. Existe, em outras palavras, um trade-off potencial entre geração de emprego no curto e no longo prazo. Esse trade-off depende, como discutido na seção anterior, da distância em que o país se encontra da fronteira tecnológica. Quanto maior for o gap tecnológico, maior será o trade-off entre geração de emprego no curto e no longo prazo.

Dadas as relações consideradas acima entre crescimento, progresso técnico e emprego, conclui-se que um projeto de desenvolvimento econômico deve levar em consideração não somente a geração de eficiências econômicas no curto e no longo prazo, mas o que isso implica para o nível de emprego, também no curto e no longo prazo.

A melhor associação possível entre geração de eficiências econômicas e geração de emprego é, claro, específica para cada país, dependendo de suas características iniciais.

Freeman \& Soete (1987), por exemplo, ao analisar o caso inglês concluem que a saída para o desemprego, gerado pela reestruturação produtiva com adoção das novas tecnologias, deve ser perseguida por sua completa inserção no novo paradigma, com base nas tecnologias de informação. Eles sugerem que, nesse paradigma, os novos postos de trabalho, que compensariam a redução do emprego implicada pela crescente automatização, estariam concentrados na construção civil e no setor de serviços, sobretudo na educação e no treinamento de trabalhadores. A ampliação

\footnotetext{
${ }^{3}$ Trajetórias tecnológicas são as formas concretas pelas quais cada paradigma tecnológico se desenvolve, mostrando o progresso de cada tecnologia no tempo. Cada paradigma pode conter várias trajetórias tecnológicas.
} 
destes dependeria, primordialmente, de fundos públicos e, portanto, de uma política de desenvolvimento e de geração de empregos elaborada e sustentada pelo Estado. Os autores enfatizam, principalmente, os gastos com educação e com treinamento de mão-de-obra, classificando-os como investimentos necessários ao novo paradigma tecnológico. Finalmente, criticam a desmontagem do welfare state, afirmando que esta vai em sentido contrário à política que deveria ser adotada pelo país. A solução proposta pelos autores para geração de emprego na Inglaterra enfatiza, assim, o ajuste do tipo "schumpeteriano" associado a uma política de emprego sustentada pelo Estado dirigida ao setor de serviços — sobretudo educação e treinamento de trabalhadores - e à construção civil.

Esse tipo de orientação para a redução do desemprego gerado pelo terceiro paradigma tecnológico, entretanto, parece inadequado para o Brasil por dois motivos principais:

1. por não haver possibilidade de inserção completa no novo paradigma, uma vez que isso requereria um volume de recursos e de capacitação tecnológica inexistentes na economia brasileira; e

2. por não se poder esperar que o Estado brasileiro, dada a precariedade de sua situação financeira, possa se responsabilizar pelo suprimento das necessidades de emprego do país.

Uma política de emprego de fato eficiente para o Brasil requer, assim, soluções específicas que levem em consideração as dificuldades atuais do Estado, a deficiência competitiva em quase todos os segmentos mais modernos, a capacitação tecnológica bem aquém da dos países de fronteira e a carência de investimentos em infraestrutura, além da necessidade de incorporar grande parte da população ao mercado de consumo.

Com o intuito de delimitar as possibilidades de atuação de uma política de desenvolvimento, incluindo a política de emprego, pretende-se na próxima seção avaliar a possibilidade de obtenção das três formas de eficiência dos segmentos produtivos. Pretende-se, especificamente, verificar quais os segmentos que permitem maior exploração de cada um dos tipos de eficiência e sua capacidade de geração de emprego no curto e no longo prazo.

\section{AS TRÊS FORMAS DE AJUSTAMENTOS E OS SEGMENTOS PRODUTIVOS}

As possibilidades de geração de emprego de cada segmento produtivo são influenciadas pelas suas diferentes capacidades de exploração das três formas de eficiência. Ou seja, o fato de um segmento ser capaz de empreender mais de um tipo de ajustamento do que de outro afeta sua capacidade de gerar emprego no curto e no longo prazo, segundo a conceituação discutida na seção anterior.

A capacidade de cada segmento produtivo em explorar as várias eficiências depende, claro, do ponto em que as tecnologias utilizadas por esse segmento se encontram nas trajetórias tecnológicas. Uma tecnologia no início de sua trajetória 
possui maior potencial de gerar inovações, de forma que o ritmo de introdução de inovações seja maior, permitindo maior exploração das eficiências "schumpeterianas”. No entanto, conforme a tecnologia avança em sua trajetória, tornando-se mais madura, as possibilidades de geração de inovações vão se reduzindo, podendo incentivar a exploração maior dos outros dois tipos de eficiência.

Assim, por um lado, os segmentos produtivos que utilizam mais as tecnologias que se encontram em ponto avançado de suas respectivas trajetórias tecnológicas estão, provavelmente, mais aptos a fazer ajustamentos dos tipos "ricardiano" e "de crescimento". Por outro, os segmentos produtivos que utilizam mais as novas tecnologias possuem, em princípio, maior capacidade de empreender ajustamentos do tipo "schumpeteriano".

É claro que uma das características de um novo paradigma tecnológico é que este é "pervasivo", ou seja, as tecnologias dele decorrentes podem ser aplicadas na maioria dos segmentos econômicos, como é o caso das tecnologias de informação. No entanto, os graus em que essas novas tecnologias afetam os diferentes segmentos são diferentes, propiciando maiores oportunidades de investimentos em alguns relativamente a outros. Além disso, as novas tecnologias não só transformam os diferentes segmentos da economia, mas também criam novos.

Em termos concretos, pode-se dizer que atualmente os segmentos produtivos que têm propiciado maior exploração das eficiências "schumpeterianas" são aqueles que utilizam mais ou estão mais relacionados às tecnologias de informação, como é o caso dos ramos pertencentes ao complexo eletrônico; os segmentos que utilizam mais as tecnologias referentes à Segunda Revolução Industrial, por outro lado, são menos passíveis de explorá-las; esse é o caso provavelmente de alguns segmentos tradicionais como a agropecuária..$^{4}$ Além disso, os segmentos produti$\operatorname{vos}^{5}$ mais passíveis de explorar as eficiências "schumpeterianas" são, ao mesmo tempo, os mais capazes de gerar oportunidades de investimentos e de aumentar sua participação no produto total. Parece ser exatamente isso o que vem acontecendo com as indústrias do complexo eletrônico que têm apresentado maior crescimento em relação às demais ${ }^{6}$.

Do ponto de vista de geração de emprego, assim, deduz-se que os segmentos mais passíveis de exploração de eficiências "schumpeterianas” são aqueles também

\footnotetext{
${ }^{4}$ A biotecnologia que teria um impacto muito forte sobre a agropecuária ainda não se constituiu de fato num novo paradigma tecnológico (ver, por exemplo, Hobbelink [1990] e Mayor [1992]).

${ }^{5}$ Inclui-se aqui os novos segmentos criados por novos paradigmas tecnológicos.

${ }^{6}$ Durante a década de 1980, o complexo eletrônico foi responsável pela retomada do crescimento nos países líderes. Entre 1980 e 1987, a participação do complexo no produto da indústria de transformação passou de $11,8 \%$ para $13,6 \%$, nos EUA; de $9,4 \%$ para $13,1 \%$, no Japão; de $9,7 \%$ para $10,6 \%$, na Alemanha; e de $7,0 \%$ para $8,3 \%$, no Reino Unido. A participação do complexo eletrônico nos investimentos da indústria de transformação ficou próxima a 20\%, nos EUA e no Japão e a $10 \%$ na Alemanha e no Reino Unido, nos anos de 1984 e 1985 (Laplane, 1992, pp. 298 e 304).
} 
responsáveis por grande parte de novos empregos que serão gerados no futuro. Mesmo que não sejam diretamente responsáveis pela criação de novos postos de trabalho, eles estão ligados às possibilidades e às alterações do emprego futuro. No curto prazo, porém, os segmentos produtivos que propiciam maior dinamismo ${ }^{7}$ à economia, como os componentes do complexo eletrônico mencionados acima, são os que mais economizam trabalho, não apenas diretamente no sentido de utilizarem proporcionalmente menos desse fator, mas também indiretamente no de reduzirem as necessidades de trabalho em outros segmentos da economia, usuários dos insumos modernos.

Diferentemente, existem segmentos produtivos, não diretamente relacionados às novas tecnologias, como a agropecuária e as indústrias de vestuário e de calçados, que germ relativamente menores oportunidades de investimento futuros. Em razão disso, provavelmente influenciarão pouco o nível de emprego no longo prazo. Mas, de modo geral, por utilizarem menos as novas tecnologias que normalmente são mais poupadoras de mão-de-obra, empregam proporcionalmente mais trabalho no curto prazo.

Um trabalho recente ${ }^{8}$ que pode contribuir para tal discussão é o de Najberg \& Vieira (1996), que verifica a capacidade de geração de emprego e de geração de crescimento de $41^{9}$ segmentos da economia brasileira no ano de 1995 , com base em metodologia que utiliza a matriz insumo-produto de $1985^{10}$, A conclusão a que chegam é que os segmentos produtivos que mais geram emprego são os mais tradicionais. Ao mesmo tempo, muitos deles são os que possuem maior encadeamento (a montante e/ou a jusante $)^{11}$, tendo maiores efeitos sobre o crescimento da econo-

\footnotetext{
${ }^{7} \mathrm{O}$ sentido do termo dinâmico, aqui, se refere às oportunidades de ampliação dos investimentos, com a criação de novos produtos e novas indústrias.

${ }^{8}$ Embora trabalhos desse tipo possam estar sujeitos a muitas críticas em virtude de problemas inerentes à metodologia do insumo-produto, eles fornecem um quadro geral útil em estudos como este.

${ }^{9}$ A desagregação da economia brasileira em 41 setores foi feita pelas autoras.

${ }^{10} \mathrm{~A}$ capacidade de cada segmento gerar emprego é dada pela seguinte equação matricial: $\mathrm{CE}=\mathrm{L}[\mathrm{I}-\mathrm{A}$ - CV] ${ }^{1}$, onde L é o vetor de coeficientes diretos de emprego (1xn ) (sendo lj a quantidade de empregos diretos necessária à produção de uma unidade de valor de produção do bem j); [I - A - CV $]^{-1}$ capta os efeitos multiplicadores keynesianos da economia, de forma que ao ser multiplicado por $\mathrm{L}$ tem-se a matriz CE que é o total de emprego direto, indireto e devido ao efeito renda que cada segmento produtivo necessita para produzir uma unidade do produto j. Para se obter o total de emprego e o total de emprego requerido por cada segmento, procede-se o seguinte cálculo: $\mathrm{TE}=\mathrm{CE}$. D, onde $\mathrm{D}$ é o total da demanda exógena - investimentos, consumo do governo e exportações - , que multiplicado por CE resulta em TE, que é o emprego total. Já a capacidade de cada segmento gerar crescimento é dada pelos índices de interligação para trás $s^{*} \mathrm{j}=\sum \mathrm{s}_{\mathrm{ij}} / \mathrm{n} / \mathrm{s}$, sendo $\mathrm{j}=1,2, \ldots \mathrm{n}$, e de interligação para a frente $\mathrm{s}^{*} \mathrm{i}=\sum \mathrm{sij} / \mathrm{n} / \mathrm{s}$ *, sendo $\mathrm{i}=1,2, \ldots \mathrm{n}$ e s* $=\sum \sum \mathrm{sij} / \mathrm{n}^{2}$

${ }^{11}$ As autoras consideraram os segmentos que mais geram crescimento econômico aqueles que têm os índices de encadeamento para trás maior do que a média e os três segmentos que possuem os maiores índices de encadeamento para a frente.
} 
mia. A classificação dos segmentos em relação à geração de emprego e ao crescimento econômico é a seguinte:

1. segmentos produtivos que estão acima da média em relação à geração de emprego, mas abaixo da média em termos de impulsionador do crescimento econômico - agropecuária, comércio, serviços prestados à família e administração pública;

2. segmentos produtivos que estão acima da média quanto àqueles dois fatores — vestuário, madeira e mobiliário, calçados, abate de animais, industrialização de café, outros produtos alimentícios, laticínios, produtos vegetais, óleos vegetais e açúcar. Observa-se, assim, que nessa categoria se encontram somente as indústrias tradicionais;

3. segmentos produtivos que estão abaixo da média nos dois fatores - extrativa mineral, petróleo e gás, refino de petróleo, equipamentos eletrônicos, químicos diversos, farmacêutica e veterinária, artigos plásticos, indústrias diversas, serviço industrial de utilidade pública, transportes, comunicações, instituições financeiras, serviços prestados à empresa e aluguel de imóveis;

4. segmentos produtivos que são grandes impulsionadores do crescimento, mas que geram emprego abaixo da média dos setores — siderúrgico, metalúrgico, de automóveis, caminhões e ônibus, de autopeças, de máquinas e equipamentos, de material elétrico, de celulose, papel e gráfica, de borracha, de elementos químicos e têxtil; e

5. por fim, os segmentos de construção civil e o de minerais não -metálicos que se encontram na média em termos de geração de emprego, mas abaixo da média quanto ao fator crescimento econômico, o primeiro, e acima da média, o segundo.

Observa-se, portanto, que entre os doze setores que mais geram empregos, nove também são importantes impulsionadores do crescimento econômico, com exceção da agropecuária, do comércio e da administração pública. Esses nove setores correspondem às indústrias tradicionais: vestuário, madeira e mobiliário, calçados e diversas agroindústrias da indústria de alimentos.

Os setores tradicionais, em grande parte, são, portanto, os que geram muito emprego e possuem grande encadeamento para trás e para a frente, apresentando forte estímulo ao crescimento econômico. Ao mesmo tempo, representam grande parte do consumo da população de menor poder aquisitivo, como pode ser observado pelas Pesquisas de Orçamento Familiar (POF) (IBGE, 1989). Alimentos, bebidas e vestuários são os maiores itens de gastos dos consumidores com salários que variam de um a oito salários mínimos.

Os setores mais voltados para o consumo da população de baixa renda, portanto, são aqueles mais tradicionais, que além disso são, na sua maioria, os maiores geradores de emprego e de crescimento econômico. Esses setores compõem o sistema agroindustrial e as indústrias de vestuário e de calçados.

Utilizando-se a conceituação acima feita entre ajustamentos econômicos e ní- 
vel de emprego, verifica-se que o trabalho de Najberg \& Vieira é importante para indicar os segmentos que mais geram emprego. Pode-se deduzir, com base na conceituação acima desenvolvida, entretanto, que esse emprego é de curto prazo, isto é, obtido a partir de ajustamentos "de crescimento" e "ricardiano". Isso porque a classificação dos diversos segmentos segundo sua capacidade de gerar emprego e crescimento econômico é feita do ponto de vista estático. Ou seja, dados os coeficientes técnicos, observaram quais setores mais encadeados para trás e para a frente, verificando a capacidade de geração de crescimento, e a partir desses resultados calcularam a capacidade de geração de emprego. A análise feita com essa metodologia, portanto, capta a situação dos segmentos num dado momento do tempo. Os segmentos produtivos classificados acima da média em termos de geração de crescimento e de emprego são, assim, importantes para dinamizar a economia e criar novos postos de trabalho a partir de políticas de aumento da demanda, ou seja, através de ajustamentos "de crescimento" ou de maior emprego dos recursos abundantes, e através de ajustamentos "ricardianos". Mas o mesmo não pode ser dito quando se considera o crescimento e a geração de emprego no longo prazo. A metodologia de matriz insumo-produto utilizada no trabalho não é capaz de captar esses efeitos no longo prazo como se irá discutir a seguir.

Em primeiro lugar, porque os coeficientes técnicos, claro, não são fixos. Conforme o país vai se capacitando tecnologicamente e introduzindo novas tecnologias, os coeficientes técnicos vão se alterando, de forma que os fatores de geração de crescimento e de emprego nos diversos segmentos também vão mudando. Em segundo, porque a modernização implica mudanças também da estrutura da demanda, afetando a capacidade dos segmentos de gerar novos postos de trabalho e impulsionar a economia. No caso de economias deficientes em termos de capacitação tecnológica, por exemplo, seus diversos segmentos utilizam poucos insumos modernos, o que faz com que a demanda por esses insumos seja então pequena. Ao empreender um processo de reestruturação produtiva, rapidamente o perfil da matriz insumo-produto tende a se alterar. Em terceiro lugar, finalmente, porque a introdução de novas tecnologias altera as requisições de trabalho, mudando a capacidade de cada segmento na contratação de mão-de-obra. Atualmente, os segmentos produtivos que mais tendem a economizar mão-de-obra com a introdução das novas tecnologias de informação são aqueles mais passíveis de automatização. Observa-se que em algumas indústrias tradicionais, ao contrário, é mais difícil a adaptação de controles automáticos em determinadas etapas de seus processos produtivos, como é o caso da indústria de vestuário e de calçados que encontram dificuldades na automação da fase da costura; da mesma forma, o setor agropecuário que sempre enfrentou dificuldades em mecanizar-se, também é menos adaptável à automatização, afetando a capacidade de geração de emprego das agroindústrias ${ }^{12}$.

\footnotetext{
12 É importante ressaltar que Najberg \&Vieira utilizaram a matriz insumo-produto de 1985. Os resultados obtidos a partir de uma matriz mais recente certamente seriam alterados, uma vez que houve muitas alterações tecnológicas de 1985 até hoje. Isso, no entanto, não invalida as principais conclusões.
} 
Um ajuste do tipo "schumpeteriano" vai, portanto, alterar os coeficientes técnicos, transformando a estrutura de demanda e de emprego do país. A determinação dos segmentos produtivos que gerarão maior emprego no futuro vai, então, depender dessas transformações. É de esperar, entretanto, que os segmentos mais prováveis de gerar emprego (no longo prazo) são os mais dinâmicos, ou seja, aqueles que têm maiores possibilidades, seja de crescimento futuro, seja de influenciar o perfil e o nível de emprego futuro. $\mathrm{Na}$ fase atual do capitalismo, as indústrias consideradas mais dinâmicas são as que compõem os complexos eletrônico, químico e metal-mecânico, além das indústrias automobilística e de instrumentos de precisão. Todas as indústrias que compõem esses complexos estão, segundo o trabalho de Najberg \& Vieira, abaixo da média em termos de geração de emprego no curto prazo. As indústrias voltadas para o consumo da população de baixa renda, mais passíveis de gerar emprego no curto prazo, não são, portanto, aquelas mais dinâmicas no longo prazo, no sentido de que não são as que mais crescem ou que mais geram novos produtos. Além disso, não estão também diretamente relacionadas ao desenvolvimento das novas tecnologias, como é o caso do setor de informática. Essas características fazem com que esses segmentos tenham menos influência sobre o perfil e o nível do emprego futuro.

A análise empreendida a partir do trabalho de Najberg \& Vieira procura detectar, dessa forma, a existência de trade-off entre geração de emprego no curto e no longo prazo na economia brasileira. Os segmentos produtivos mais tradicionais gerariam mais emprego no curto prazo, enquanto os mais dinâmicos seriam os maiores responsáveis direta ou indiretamente pelo nível e perfil futuro do emprego. A discussão feita até agora nesta seção levou em consideração apenas o emprego no setor industrial e agropecuário. O setor terciário, no entanto, é o maior responsável pelo emprego e tende a se tornar ainda mais importante nesse aspecto na atual fase de desenvolvimento capitalista.

Tomando-se novamente o trabalho anteriormente mencionado, pode-se observar a importância do setor terciário, com a construção civil, na geração de emprego ao ponderar a participação do setor pela demanda final. Com a ponderação ${ }^{13}$

Devido às características dos segmentos tradicionais, de serem menos passíveis de automatização, acredita-se que continuam sendo mais empregadores de mão-de-obra do que os segmentos considerados mais dinâmicos.

${ }^{13}$ Essa ponderação foi feira de forma simples, apenas para se ter uma ideia da capacidade de geração de emprego por segmento produtivo, segundo a participação de cada um na demanda final total. Utilizando-se dados da matriz insumo-produto de 1990, calculou-se a proporção com que cada segmento participava na demanda final, multiplicando-se $\mathrm{cm}$ seguida essa proporção pelo número de empregos totais gerados pelo respecrivo segmento em decorrência de uma demanda de US\$ 1 milhão. Assim, por exemplo, a indústria de construção civil, segundo dados de Najberg \& Vieira (1996), gera 180 empregos no total a cada US\$ 1 milhão de demanda. No entanto, a demanda final por produtos da construção civil representa cerca de $13,5 \%$ da demanda final total, de forma que esse segmento tenha uma participação muito grande no total de empregos da economia. Com esse cálculo supôs-se, assim, que um aumento na demanda total afete de forma diferente a demanda dos diversos segmentos, de modo que a geração de emprego por segmento deva ser ponderada pela participação deste na demanda total. 
tem-se alteração na ordem dos segmentos que mais geram emprego. Os segmentos que mais empregam pessoal passam a ser: 1) administração pública; 2) construção civil; 3) comércio, e 4) serviços prestados à família. A partir dessa classificação pode-se fazer algumas inferências sobre a capacidade desses segmentos de gerar emprego no Brasil, na fase atual.

Em relação ao emprego público, as tendências observadas atualmente no país mostram que há propensão ao enxugamento do quadro de servidores públicos em todos os níveis - federal, estadual e municipal. Segundo dados do Ministério do Trabalho (Brasil, 1998) houve redução do nível de ocupação na administração pública no Brasil de 0,29\% em 1996, de 0,72\% em 1997 e de 0,06 \% até março de 1998. Pode-se concluir que o setor público provavelmente não gerará muitos empregos, pelo menos no curto prazo. Soma-se a isso, de acordo com o trabalho de Najberg \& Vieira, o fato de a administração pública estar bem abaixo da média em relação à dinamização do crescimento econômico.

Outro segmento potencialmente importante para a geração de emprego é o da construção civil. De acordo com dados do DIEESE (1995), esse setor, no município de São Paulo, vem registrando considerável redução no nível de emprego desde 1988, chegando em outubro de 1995 a um índice de 75,2 em relação a abril/88=100. No Brasil, segundo dados do Ministério do Trabalho (Brasil, 1998), o emprego na construção civil apresentou queda de 1,47\% em 1996 e aumento de 1,11 \% em 1997. Embora tenha sido registrado aumento nos postos de trabalho nesse segmento em 1997, a construção civil depende em grande medida de coordenação e investimentos do Estado, tanto na recuperação do financiamento à construção de moradias quanto em investimentos em infra-estrutura. A situação financeira atual do Estado, entretanto, tem inviabilizado uma atuação mais firme do governo nessas áreas, o que o impede de exercer um papel importante sobre o emprego nesse segmento. O terceiro segmento que mais gera emprego é o comércio. Esse setor, da mesma forma que a construção civil, apresentou resultado negativo em termos de emprego em 1996 (-0,4\%) e positivo em 1997 (1,8\%). No entanto, como visto anteriormente, são pouco dinâmicos em relação ao crescimento econômico. Dependem, na verdade, do aumento do nível de atividade econômica e da renda ou, em outras palavras, do crescimento da produção de outros setores. De modo geral, o setor de serviços é pouco impulsionador do crescimento econômico, como classificado acima. Embora não se tenha dados desagregados para serviços prestados à família, os dados do Ministério do Trabalho indicam que serviços, de maneira geral, seguiram a tendência verificada nos dois segmentos mencionados acima - redução no nível de ocupação de 0,58\% em 1996 e aumento de 0,81\% em 1997.

Conclui-se que, em primeiro lugar, o setor terciário é em geral pouco dinâmico no sentido de impulsionar o crescimento econômico; em segundo, que alguns segmentos para tornarem-se importantes geradores de emprego no futuro dependem, em grande parte, da restauração da capacidade do Estado de financiamento e coordenação, como é o caso dos empregos públicos e da construção civil, e do crescimento do produto e da renda, como é o caso do comércio e dos serviços familiares; e, em terceiro lugar, que esse setor também está sujeito à reestruturação 
tecnológica e organizacional que reduz a necessidade de trabalhadores. Isso não quer dizer que o setor terciário não venha a cumprir um grande papel como empregador no futuro - seguindo a tendência mundial de estar aumentando sua participação em termos de emprego - nem que alguns segmentos do setor terciário não apresentem também dinamismo próprio, como é o caso de muitos serviços prestados à família. O que se quer enfatizar aqui é que no curto prazo esse setor não tem conseguido compensar o desemprego gerado por outros setores, o que sugere que deve ser pensada uma política global de emprego que considere todas as potencialidades possíveis de todos os setores para que juntos possam contemplar a inserção competitiva do país no cenário internacional, o crescimento econômico e o bem-estar social.

\section{CONCLUSÃO}

A principal conclusão a ser destacada neste artigo é a de que a busca de eficiência "schumpeteriana" é indispensável para a economia brasileira alcançar um crescimento sustentável. No entanto, os investimentos feitos para atingir tal objetivo devem agravar o problema do desemprego, de modo que medidas dirigidas à exploração dos outros dois tipos de ajustes devam ser efetuadas simultaneamente, como forma de amenizar os efeitos perversos do progresso técnico sobre o nível de emprego.

Em termos de segmentos produtivos conclui-se que, embora todos os segmentos sejam passíveis de explorar todos os tipos de ajustamentos, os segmentos mais tradicionais utilizam em grau menor as novas tecnologias. Ao mesmo tempo são aqueles em melhores condições potenciais de gerar empregos. Dessa forma, o problema do desemprego no curto prazo poderia ser amenizado pelos ajustamentos mais "de crescimento" e "ricardiano" com base nesses segmentos. Isso seria importante também no sentido de que o aumento da produção dos segmentos mais tradicionais estaria de acordo com a preocupação de incorporação de segmentos excluídos da população no mercado de consumo.

O emprego no longo prazo, entretanto, é influenciado primordialmente pelos ajustamentos "schumpeterianos", de modo que não se possa deixar de investir nos segmentos mais dinâmicos, aqueles mais aptos a explorar as eficiências "schumpeterianas”. É claro que esses segmentos também poderiam aumentar o nível de emprego com ajustamentos "de crescimento", sobretudo. No entanto, os recursos exigidos para aumentar a capacitação tecnológica do país são altos, além de esses segmentos precisarem de mais investimentos para gerar uma unidade de trabalho. Infere-se, assim, que a quantidade de postos de trabalho gerados pelos segmentos mais dinâmicos não será capaz de resolver o problema do emprego no curto prazo.

Conclui-se, em outras palavras, que uma política de crescimento eficiente para o Brasil não pode basear-se, apenas nem principalmente, nos segmentos tradicionais, que são os maiores geradores de emprego no curto prazo, devendo contemplar simultaneamente aqueles capazes de gerar eficiência dinâmica para a economia e 
aumentar o emprego no longo prazo. Como, no entanto, é difícil imaginar que o Brasil possa suportar um agravamento ainda maior em sua já péssima distribuição de renda, não há como deixar de salientar a importância de utilizar os segmentos tradicionais como importantes fontes de novos empregos, não se esquecendo de que também devem ser submetidos a ajustes "schumpeterianos" para aumentar sua produtividade e competitividade. Ainda mais porque esses segmentos são os mais importantes para o consumo da população de baixa renda. É preciso, em suma, combinar em grau adequado as diversas eficiências para atravessar esse período de intensas transformações, procurando associar a exploração da eficiência econômica com o aumento do bem-estar da população.

É importante enfatizar, finalmente, que as conclusões acima não descartam a possibilidade e a necessidade de acordos institucionais que amenizem o problema do desemprego, como a redução de jornada de trabalho, que entre outras soluções tem sido bastante discutida atualmente nos países desenvolvidos, sobretudo nos europeus. Além disso, não deixa de reconhecer que grande parte do desemprego atual no Brasil se deve ao crescimento insuficiente do produto, que o programa de estabilização e as crises externas têm acarretado. $\mathrm{O}$ artigo procurou apenas fazer um recorte teórico sobre a questão específica do trade-off existente entre geração de emprego no curto e no longo prazo.

\section{REFERÊNCIAS}

BALTAR, P. E. A., HENRIQUE, W. (1994) “Emprego e renda na crise contemporânea no Brasil”. In: OLIVEIRA, C. A. B. et al. (Org.). O mundo do trabalho - Crise e mudança no final do século. São Paulo: Página Aberta, p. 605-618.

BRASIL Ministério do Trabalho. Brasília, 1998.

DIEESE (1995). Tabela 5A.B. Boletim do Dieese. São Paulo: v. 15, nº 177, p. 21.

DOSI, G. (1984) Technical Change and Industrial Transformation - The Theory and Application to the Semiconductor Industry. London: MacMillan Press, 1984, 338p.

DOSI, G. (1988) '"Institutions and Markets in a Dynamic World". The Manchester School, vol. LVI, $\mathrm{n}^{\circ}$ 2, pp. 119-146.

IBGE. (1989) Sistema nacional de índices de preços ao consumidor — Estrutura de Ponderações. Pesquisa de Orçamentos Familiares. Rio de Janeiro: IBGE.

FREEMAN, C. \& SOETE, L. (1987) "Policy Conclusions". In: Technical Change and Full Employment. FREEMAN, C. \& SOETE, L. (eds) Oxford, NewYork: Basil Blackwell.

HOBBELINK, H. (1990) Biotecnologia: muito além da revolução verde. Rio de Janeiro.

LAPLANE, M. F. (1992) O complexo eletrônico na dinâmica industrial dos anos 80. Campinas: UNICAMP, Tese (Doutoramento em economia), Universidade Estadual de Campinas.

MAYOR, E (1992) “As biotecnologias no início dos anos noventa: êxitos, perspectivas e desafios”. Estudos Avançados, 6(16).

NAJBERG, S. \& VIEIRA, S.P. (1996) “Emprego e Crescimento Econômico: Uma contradição”. Textos para discussão do BNDES, n” 48, setembro.

PORTER, M. E. (1993) A Vantagem Competitiva das Nações. Rio de Janeiro: Campus. 